\title{
OS DESAFIOS DA EDUCAÇÃO INCLUSIVA NA ESCOLA PÚBLICA
}

\author{
Antônio Fernando Ferreira Santos ${ }^{1}$ \\ Juci de Brito Alcantara ${ }^{2}$ \\ Paulo Sérgio Paixão de Jesus ${ }^{3}$ \\ Silvonilton Carvalho Bastos ${ }^{4}$
}

\begin{abstract}
RESUMO
Esta pesquisa discorre a respeito dos desafios encontrados na escola pública, no seguimento da educação inclusiva, pois sempre apresentado dentro do contexto histórico, em um panorama de obstáculos que dificultaram o acesso e inserção destes alunos neste ambiente escolar público. Por meio de através de uma síntese de alguns materiais, a respeito das principais dificuldades no contexto escolar da educação inclusiva na rede pública de ensino. O tema tem sido discutido, mas não de forma exaustiva, tão pouco específica, entretanto é um assunto de significativa relevância, visto que, o tema é caracterizado de forma contemporânea. Contudo, é necessário estudos, pesquisas e aplicações, pois desta forma, não ficará apenas nos confins das gavetas, saindo da teoria e adentrando na prática. De acordo com a característica desta pesquisa, que tem características nos aspectos bibliográficas e exploratórias, e através desta, poderão surgir possibilidades de identificar e compreender que as dificuldades são existentes. Entretanto, existem formas criativas que poderão ser incluídas no processo de ensino e aprendizagem no contexto da inclusão do educando no ambiente educacional
\end{abstract}

Palavras-chave: Educação Inclusiva, Desafios.

\section{RESUMEN}

Esta investigación discute los desafíos encontrados en las escuelas públicas, siguiendo la educación inclusiva, como siempre se presenta en el contexto histórico, en un panorama de obstáculos que obstaculizaron el acceso e inserción de estos estudiantes en este entorno escolar público. A través de una síntesis de algunos materiales, sobre las principales dificultades en el contexto escolar de la

${ }^{1}$ Mestrando do Curso de Ciências em Educação pela Faculdade Interamericana de Ciências Sociales (FICS).Pôs Graduação em Metodologia do Ensino da Matemática( FAAC). Email: fernando331011@hotmail.com

${ }^{2}$ Mestrando em Ciências da Educação pela Faculdade Interamericana em Ciências Sociais (FICS). Pós-Graduado em Metodologia do Ensino da Educação Física e do Esporte Escolar pela Faculdade da Cidade do Salvador. Pós-Graduado em Atividade Física, Educação e Saúde para Grupos Especiais pela Faculdade Visconde de Cairu da Fundação Visconde de Cairu, através do CEPPEV Centro de Pós-graduação e Pesquisa Visconde de Cairu. E-mail jjjussa3@gmail.com

${ }^{3}$ Mestrando do Curso de Ciências em Educação pela Faculdade Interamericana de Ciências Sociales (FICS). Bacharel em Serviço Social, Licenciado em Pedagogia, Licenciado em História Especialista em Educação Especial Inclusiva, Especialista Psicopedagogia Clinica e Institucional. Especialista em Neuropsicopedagogia, Especialista em História da Cultura Afro, Indígenas Brasileira, Especialista em Tecnologias da Educação, Especialista em Educação Infantil e Seriem Iniciais. Especialista em Coordenação e Gestão Pedagógica. Especialista em Docência do Ensino Superior e Especialista e Educação de Jovens e Adultos - EJA, Especialista em Políticas Sociais e Gestão. Social, Coordenador Pedagógico da Fundação da Criança e do Adolescente (FUNDAC). E-mail: paulovitty@yahoo.com.br.

${ }^{4}$ Mestrando em Ciências da Educação pela Faculdade Interamericana em Ciências Sociais (FICS. Graduado em Licenciatura em Matemática Universidade Católica do Salvador (UCSAL), Bacharel em Engenharia Ambiental Faculdade Área 1, Pós-graduado em Educação Matemática, Universidade Católica do Salvador (UCSAL), Pós-graduado em Engenharia de Segurança do Trabalho Universidade Salvador (UNIFACS), Pós-graduado em Geotecnologias Instituto de Qualificação Profissional (IQUALI). Email:bastossilvonilton@gmail.com 
educación inclusiva en el sistema escolar público. El tema ha sido discutido, pero no de manera exhaustiva, tampoco es específico, sin embargo es un tema de relevancia significativa, ya que el tema se caracteriza de manera contemporánea. Sin embargo, los estudios, la investigación y las aplicaciones son necesarios, ya que de esta manera, no solo se quedará en los confines de los cajones, dejando la teoría y entrando en la práctica. De acuerdo con la característica de esta investigación, que tiene características en los aspectos bibliográficos y exploratorios, ya través de ella, posibilidades de identificar y comprender que puedan surgir las dificultades existentes. Sin embargo, existen formas creativas que pueden incluirse en el proceso de enseñanza y aprendizaje en el contexto de incluir al alumno en el entorno educativo.

Palabras clave: Educación Integrada, Desafíos.

\section{INTRODUÇÃO}

Este estudo tem como objetivo refletir sobre a trajetória, o marco legal e quadro atual dos desafios da Educação Inclusiva na escola pública.O processo da inclusão na educação, é essencialmente importante e necessário, pelo qual os alunos, terão possibilidades e oportunidades de fazerem parte de um contexto social e educacional, eliminando a probabilidade de rejeição por conta de suas condições especificas, afastando a discriminação e julgamento, de forma a permitir e facilitar o seu acolhimento. Os obstáculos inerentes ao processo da inclusão ainda são considerados tabus sociais, que precisam de rompimento.

No contexto educacional, a definição de inclusão segundo o dicionário Michaelis, é a política educacional que consiste em incluir indivíduos com necessidades especiais em turmas consideradas regulares, fazendo-os participar de atividades não só educacionais, mas também comunitárias, esportivas e sociais.

Nos meados do século XV, exatamente em 1948, com a Declaração Universal dos Direitos Humanos, a prioridade passou a ser a liberdade e a igualdade entre as pessoas. Trazendo de forma efêmera uma ponderação importante a respeito da inclusão.

O percurso histórico da educação inclusiva brasileira, nos mostra que a partir da promulgação da Constituição Federal de (1988), criou-se possibilidades de ter a educação como direito de todos e, dever do Estado e da família, além de falar da acessibilidade e permanência na escola. Já no Art. 208, inciso III, fala do atendimento educacional especializado aos portadores de deficiência. Contudo a educação inclusiva não aborda apenas pessoas com deficiências, mas a garantia de estabelecer relações indissociáveis dessas pessoas com a sociedade.

A Lei de diretrizes e bases da educação nacional Lei oㅜ 9.394/1996 (LDB): 
exclusiva em educação especial para fins de apoio técnico e financeiro pelo poder público (BRASIL, 1996, [s.p.])

No entanto, há um caminho extenso para percorrer, necessitando ainda de muita luta para a superação da falta de conhecimento e até mesmo a obscuridade, que como causa, fortalece a ignorância, preconceito e exclusão, ainda que, cheguemos à convivência de todos, sob o estandarte do respeito e do acolhimento fraterno.

Dessa forma, a inclusão é um movimento indispensável para a evolução do ser humano no caminho da construção da sua liberdade com sujeito de uma sociedade.

De acordo com a Declaração de Salamanca, documento elaborado em 1994, apresenta que a tendência em política social durante as duas últimas décadas tem sido a de promover integração e participação e de combater a exclusão. Inclusão e participação são essenciais à dignidade humana e ao desfrutamento e exercício dos direitos humanos (BRASIL,1997.p.6).

Dentro do contexto educacional, os desafios proporcionados pelo período da ainda educação tradicional, que de certo modo, mantinha um olhar distante da inclusão escolar, dificultava as ações para atender as particularidades dos alunos.

Segundo Panarotto e Silva (2014), no século XX os princípios da inclusão ganharam força, o que não quer dizer que já tenhamos superado todos os obstáculos e resistências, mas as linhas estão definidas e até mesmo assumidas pela sociedade brasileira.

Segundo a Declaração de Salamanca (1997), pessoas com necessidades educacionais especiais (PNEE) se referem a todas as crianças e jovens cujas necessidades decorrem de sua capacidade ou de suas dificuldades de aprendizagens.

Diante de todo este cenário de mudanças com relação a inclusão escolar para crianças ou adolescentes com necessidades especiais educativa, é perceptível a relevância no contexto da inclusão social, como afirma a Declaração Universal dos Direitos Humanos de 1948, que abordou a liberdade e a igualdade entre as pessoas, que trouxe para a atualidade reflexões e debates.

Os debates com relação ao campo da inclusão social, estão ganhando corpo e relevância, de forma que servem de indicadores para a fomentação de antigos pensamentos que canalizavam para o sistema de exclusão e discriminação. 
A Declaração de Incheon (2015), aponta que a Inclusão e equidade, são bases de transformação no compromisso da luta contra a exclusão no processo educacional, a disparidade e desigualdades no acesso. Tendo como meta principal atingir a totalidade de acesso ao mais desfavorecidos, especialmente aqueles com deficiências, a fim de assegurar que ninguém seja negligenciado.

Entretanto, o processo de inclusão das necessidades especiais não se caracteriza apenas em preparar ou incluir fisicamente o aluno no espaço escolar. De fato, são necessárias estruturas adequadas e acessibilidade inclusiva. Mas, faz-se necessário um Projeto Político Pedagógico bem estruturado, professores preparados e um trabalho de sensibilização e conscientização dos alunos desprovidos de necessidades especiais. Desta maneira, dar-se-á o início de uma nova realidade para uma boa convivência no espaço escolar, ou pelo menos tentar esta boa convivência.

Mesmo com todo aparato da legislação, existe muito trabalho a realizar, para criar e oferecer não só oportunidades, mas que estas oportunidades sejam justas de acordo com as limitações individuais. O respeito com as diferenças deve ser levado ao cume da seriedade, apresentar os projetos com criticidade, contudo, sem julgamento. Pois, caso isto aconteça, será um retorno ao caminho da exclusão.

Faz-se necessário uma reflexão quanto ao direito que todos tem à acessibilidade, ao espaço escolar, as necessidades específicas educativas, que sejam efetivamente acolhidas e encaminhadas ao atendimento individualizado, dentro de suas especificidades. Além disso, entender que não existe diferença nos direitos entre pessoas com de necessidades especiais e os ditos como "normais", cada ser humano é único, merece respeito, atenção e sobre tudo ser tratado com dignidade.

\section{OS DESAFIOS DA EDUCAÇÃO INCLUSIVA NA ESCOLA PÚBLICA}

O acesso à escola é um direito de todos sem restrições, as diversidades e a inclusão de pessoas com qualquer tipo de deficiência. Infelizmente, isso não é uma realidade nas escolas públicas do nosso país. A educação precisa ser respeita principalmente quando se trata da Educação Especial, que nas últimas décadas foi discriminada e negada o direito a pessoa com necessidades especiais frequentarem a escola no ensino regular. Segundo o Ministério da Educação (MEC) a Educação Especial é entendida como: 
conjunto de recursos e serviços educacionais especiais, organizados institucionalmente para apoiar, complementar, suplementar e, em alguns casos, substituir os serviços educacionais comuns (...) em todas as etapas e modalidades da educação (BRASIL, 2001, p.39).

A fim de atender essa demanda de púbico, a lei brasileira tornou obrigatória o ingresso desses alunos nas escolas, trazendo uma grande vitória alcançadas para as famílias, mas ainda existem obstáculos em aceitas esses alunos nas redes públicas de ensino como: preconceitos, medo e muita discriminação.

O sistema educacional é desigual isso está bem evidente nas classes sociais. Existem escolas de alto nível em que esses estudantes tem estrutura educacional a ser alcançada, paralelo a isso a grande maioria tem pouco acesso e grande dificuldades e carências. Essa é o perfil das escolas públicas do nosso país.

A Lei das Diretrizes e Bases da educação (LDB) surgiu para que exista uma educação igualitária principalmente para educação inclusiva, não apenas para as crianças como também para jovens e adultos, é preciso que exista um olhar diferenciado para essa clientela.

Diante disso é importante que educação inclusiva seja uma atividade mútua e simultânea, trabalhando com o mesmo objetivo, de que conhecimento seja alcançado, independente da sua deficiência, mas para que isso aconteça deve existir o convívio social. A educação inclusiva estabelece uma realidade negativa nas escolas e cobra um ensino igualitário com adaptações curriculares e métodos pedagógicos para conseguir avaliar esses alunos.

A ideia é que todos os alunos com e sem necessidades especiais estejam inseridos no mesmo ambiente escolar. Isso é uma grande dificuldade e de aceitação de alguns educadores pois "é uma espécie de tolerância da presença do aluno em sala de aula e o que decorre dessa situação é a perpetuação da segregação, mesmo que o aluno esteja frequentando um ambiente escolar comum" (BRASIL, 2006, p. 73). Vale ressaltar que a escola é um direito de todos, sem restrições. Além disso, o MEC ainda promove uma sala comum para esses indivíduos e isso contradiz o processo da educação inclusiva que fala que todos os alunos precisam convier juntos na mesma classe para poder se socializar e ter uma boa convivência com os colegas, e em todo ambiente escolar.

A escola é um local de socialização, portando deve respeitar as diferenças diminuindo assim, qualquer tipo de preconceito. Conviver com igualdade é a maneira que os alunos conseguirão harmonia com os colegas, fazendo com que o ambiente 
escolar para eles seja um pequeno universo, acabando assim com um mito da desigualdade. Não existindo vencedor nem perdedor. Significa que a convivência dos alunos é o objetivo principal da educação inclusivo, é através do convívio com o outro, que o individuo aprende e todos saem ganhando, ou seja, através da diferença que o aprendizado acontece.

A implantação da educação inclusiva na escola que possui seu histórico tradicional, tem bastante resistência em aceitar qualquer tipo de mudanças, como a inclusão e aprendizagem para todos, porém para que essa transformação aconteça é necessárias políticas públicas para investir na educação e na qualificação dos professores considerando esse tema importante. Os desafios dos professores e das escolas são bastante, pois eles não se acham preparados para receber essa clientela. As escolas não tem estruturas adequadas, eles se sentem incapazes de ensinar alunos com deficiência visual e auditivos, por exemplo, por não ter apoio de profissionais especializados e assim deixam passar despercebido e não conseguem propor a inclusão desses alunos.

É notório a necessidade imediata de órgãos públicos a tomarem providencias em relação a essa lei, como por exemplo: Capacitando os professores, possuindo salas com atendimentos educacionais especializadas, profissionais e várias adaptações no ambiente escolar para que alunos e professores consigam se adequar a essa nova realidade de ensino, mas infelizmente ainda está muito longe de conseguirmos alcançar essas mudanças que leve a inclusão nas escolas. $O$ processo de ensino aprendizagem nunca será constante nem regular, pois os professores pensam de maneira diferentes e a grande maioria das vezes nem sempre o resultado é positivo.

Esse trabalho traz uma reflexão sobre a educação inclusiva no âmbito das escolas publicas, analisando como as escolas estão recebendo esses alunos para garantir a sua inclusão. Estudos bibliográficos mostram que as escolas não estão nem um pouco preparadas para inserir esses portadores de necessidades especiais. As grandes dificuldades da educação inclusiva nas escolas é a necessidade de criar um ambiente escolar propício para esses alunos especiais. Pois, precisa desenvolver estratégias de ensino e aprendizagem adaptadas para essa clientela e mudar o modo de pensar e de agir com as diferenças, sem preconceitos, fazendo com que o aluno tenha um bom convívio em todo ambiente escolar. Conseguindo resolver essas dificuldades, talvez as escolas estejam mais preparadas para receber 
esse público, que não são aceitos até hoje, nas redes de ensino por serem diferentes.

A estratégia para conseguir inclusão de alunos com necessidades abrange vários fatores, como por exemplo: Conhecer 0 aluno na sua totalidade. A necessidade de ter uma formação continuadas dos professores, e apoio da familiar deve ser os primeiros itens a ser pensado em todo corpo docente. $O$ educador precisa mudar suas estratégias, criar métodos e práticas para tentar alcançar a aprendizagem desse público. Conhecer o ambiente em que o aluno está inserido é importante, para que ele consiga se afeiçoar ao meio, melhorando assim seu aprendizado.

Para mudar o perfil da escola atual para inclusiva, não basta apenas leis e metodologias de ensino, é necessário conscientizar e respeitar as diferenças, e mudar os padrões que estão inseridos a bastante tempo na rede de ensino. Educação é o direito de todos sem distinção, é preciso partir do princípio que todos nós somos diferentes e temos nossa individualidade. Trazer discussões sobre a inclusão com a família e toda a comunidade escolar seria outra alternativa para melhorar a inclusão, é importante conhecer as necessidades desses alunos e assim traçar uma meta de ensino que seja bom para todos (MANTOAN, 2003)

A educação inclusiva permite que uma pessoa com necessidades especiais consiga inserir na rede de ensino regular e consiga aprender de acordo com as suas necessidades. Neste caso, não é apenas a presença do aluno e sim o seu aprendizado. Mas para que isso aconteça a escola e os profissionais de educação tem que estar preparados para recebê-los, fazer uma adaptação curricular de acordo com a necessidade do aluno. Os desafios são grandes quando se trata de inclusão. Existem muitas barreiras ainda para serem vencidas, porém a lei está aí para amparar esses alunos que são bastante discriminados e não aceitos no meio escolar tradicional. A inclusão deveria ser uma coisa comum e cotidiana na rede pública de ensino, mas as escolas publicas ainda estão despreparadas para lidar com isso.

Os educadores precisam respeitar o ritmo de aprendizado desses alunos para poder conseguir seu objetivo, cada um tem sua maneira de aprender e quando se trata alunos especiais é preciso ter paciência e cautela com essa clientela. Não deixa de ser um desafio para o educador, mas pode ser uma maneira de melhorar seu trabalho em sala de aula.

Respeitar as diferenças pode significar muito para poder tratar a inclusão de maneira mais humana e com direitos iguais. Isso faz com que a sala de aula seja 
mais atraente, proporcionando o processo ensino aprendizagem fluir de maneira melhor para todos.

Alguns educadores acham que a inclusão deve acontecer gradativamente, ou seja, a medida que esses alunos sejam incluídos. Os educadores deverão fazer com que aos poucos ele consiga a se adaptar ao ambiente escolar. Enquanto a educação não for prioridade para os governantes, o caminho fica mais difícil para a inclusão. Em vista disto, é preciso a união de todos para essa transformação acontecer.

\section{OS DESAFIOS DA EDUCAÇÃO INCLUSIVA, NA PERSPECTIVA DA IDENTIFICAÇÃO DOS EDUCANDOS AUTISTAS}

O transtorno do espectro autista é um termo que engloba de uma forma geral um grupo de distúrbios de desenvolvimento do celebro. E refere-se a uma série de condições caracterizada por dificuldades em habilidades sociais, comunicação e por padrões restritos e repetitivos de vários comportamentos, interesses e atividades.

Esta termologia foi primeiramente publicada na edição do Manual de classificação de Doenças Mentais da Associação Americana de Psiquiatria, o DSMV (2014). Conhecido mais popularmente por autismo, o TEA está sendo mais abordado nas mídias atualmente, mas em se tratando historicamente é um tema relativamente novo.

A inclusão é um direito adquirido por lei, é dever da escola receber todos os educandos e dar todo suporte que esta necessidade precisar. O educando com TEA necessita de um atendimento especializado, pois para que haja aprendizado é preciso adequação tanto na pratica de ensino quanto do ambiente escolar. A partir das práticas pedagógicas inclusivas, que transpõem as dificuldades e barreiras que possam prejudicar e dificultar ainda mais a inserção deste educando na classe regular, dificultando assim a sua aprendizagem. A inclusão escolar trouxe a educação especial para dentro das escolas regulares, sendo uma grande conquista. A Constituição Federal de 1988 que nos eu Art. 208 é dedicado à educação, e diz que "o dever do Estado com a Educação será efetivado mediante a garantia do, seção III- atendimento educacional especializado aos portadores de deficiência, preferencialmente na rede regular de ensino" (BRASIL, 1988).

O profissional de educação precisa repensar o currículo com atividades pensadas nas especificidades do educando com TEA, é preciso avançar além das aulas, o atendimento especializado dentro da escola sempre será um diferencial, 
pois orientará o educador na sua pratica, como também trará uma outra visão do educando com TEA em outros ambientes que não é apenas sala de aula (MANTOAN, 2003).

Segundo a teoria de Vygotsky, o processo de construção conjunta é continua do conhecimento passa a ser um caminho para a superação das dificuldades. Não existe uma receita pronta, ou nenhum método milagroso. Ter um educando com TEA, é ter a oportunidade de explorar novas experiências. De adaptar antigas praticas ás necessidades dos educandos. Para fazer a inclusão acontecer, precisamos ultrapassar algumas barreiras sejam visíveis ou invisíveis. E potencializar as capacidades dos educandos com TEA, não subestimando suas competências, buscar novos recursos, e utilizar o que já temos na escola. Ter uma parceria com a família e outros profissionais que atendam a este educando. A inclusão nãos e faz sozinha; é preciso muitas mãos, mas ao educador cabe o papel essencial de enxergar as possibilidades de cada educando além do seu diagnóstico, respeitando suas particularidades (VYGOTSKY, 1998)

A falta de capacitação e o receio dos educandos com as mais variadas deficiências tem levado professores no Brasil inteiro a terem seus medos frente ao desafio da inclusão. Não basta incluir é preciso integrar de fato, pois o processo de inclusão do educando no ensino regular é para além do acesso e permanência no espaço escolar, mas sobretudo proporcionar as reais e imprescindíveis condições para que os mesmos possam aprender. É preciso que o educando com deficiência vivencie experiências com o outro para que de fato a socialização aconteça facilitando o processo de ensino e aprendizagem. Isso só ocorrerá se a escola estiver devidamente organizada tanto no aspecto funcional como também estrutural para receber este educando e incluí-lo. Partindo do princípio da inclusão de todos deve ser levado em conta a adaptação do currículo de acordo com às necessidades dos educandos, de maneira que promova oportunidades e que haja adequação as habilidades e interesses diversos.

No ambiente escolar a Educação Especial deve fazer parte de modo natural, sobretudo na Educação Básica, no intuito de assegurar aos educandos que precisam de apoio especializado e de ações pedagógicas específicas, uma intervenção mais eficiente no processo de ensino e aprendizagem, dentro do contexto no qual está inserido.

Constitui a inclusão escolar, portanto, uma proposta principalmente do ponto de vista político que seja correta representando valores simbólicos importantes, que 
garantam oportunidades educacionais e igualdade de direitos para todos, em um ambiente educacional que favoreça. A realidade brasileira, reconhecidamente ampla e diversificada precisa de mais investimentos em pesquisa.

Ao pensar a Educação Inclusiva no Brasil é preciso refletir acerca da superação dos obstáculos impostos pelas diversas limitações do sistema regular de ensino o que acaba defrontando com as dificuldades operacionais e pragmáticas reais e presentes como, por exemplo, os profissionais de apoio, professores devidamente qualificados, e infraestrutura das escolas bem adequadas para essa demanda, nesse Brasil afora inclusive em grandes centros ainda carece de boas estruturas e isso é fato.

Notadamente percebe-se que no Brasil a viabilidade do modelo da escola na perspectiva da inclusão se depara com a dificuldade dos recursos humanos, especificamente dos professores das classes regulares, que precisam ser devidamente capacitados para que possam transformar sua prática educativa. A inclusão de todos efetivamente vai depender muito da formação e qualificação dos docentes e de todos os envolvidos nesse processo para que os objetivos sejam alcançados (CARVALHO, 2000).

A quebra de paradigma e as mudanças necessárias quando implicam novos desafios e todas as possíveis demandas socioculturais trazem consequências indiscutíveis. Quando se almeja mudanças é preciso ter cuidado com o que já foi conquistado e atenção com o que se pretende conquistar.

Nas práticas pedagógicas no ambiente escolar e as próprias pesquisas científicas tem comprovado experiências relacionadas as variadas dificuldades para integrar o educando com deficiência e que precisa de atendimento especializado. Demonstrando os descompassos de diversos fatores como de natureza familiar, institucionais e socioculturais. Uma grande parte dos sistemas educacionais tem como base a concepção médico-psicopedagógico principalmente quanto a identificação e ao atendimento dos educandos com deficiência.

Em uma perspectiva global no contexto da escola no seu projeto pedagógico, os currículos, a própria gestão escolar, os conselhos, até mesmo a comunidade existente no entorno da escola precisam firmar parcerias para redimensionar numa perspectiva de fazer frente a todas as dificuldades e contextos de uma educação efetivamente para todos. As diretrizes e bases da educação nacional estabelece princípios que democratizam a Educação Inclusiva no país. 
Constitucionalmente já existe uma integração dos portadores de necessidades educativas especiais no sistema regular de ensino. Pelo menos há uma década. Mas na realidade escolar tal diretriz ainda não gerou o esperado efeito que seria as mudanças necessárias para que crianças, jovens e adultos com deficiência sejam atendidos na rede regular de ensino (CARVALHO, 2000).

O que se busca incessantemente no Brasil é uma política nacional de Educação Especial na perspectiva da Educação Inclusiva que tenha como objetivos, a formação e qualificação dos professores, a participação permanente da família e da comunidade e uma articulação dos setores envolvidos dentro de uma perspectiva de políticas públicas eficientes, para a garantia do acesso e permanência dos estudantes com deficiência, transtornos globais do desenvolvimento e altas habilidades ou superdotação, no ensino regular.

Mas não apenas os ditames burocráticos são percalços no contexto da Educação Inclusiva no Brasil e, sobretudo na rede pública de ensino, muitos outros empecilhos contribuem para a efetivação de um trabalho inclusivo. Destaca-se a resistência das instituições e dos profissionais ao preparo profissional e a busca constante por conhecimento e aprimoramento de suas ações, bem como às mudanças e inovações. É preciso pensar em mudanças nas atitudes dos profissionais envolvidos e das famílias que muitas vezes emperram o trabalho das escolas em detrimento de interesses próprios e até de preconceitos.

Há ainda um longo caminho a ser percorrido para que a inclusão se realize de fato e para que os profissionais encontrem estratégias e recursos que atendam as especificidades dessa demanda sem que estes sejam segregados. Portanto reconhecer que a Educação Inclusiva no país é um desafio de todos e que as melhoras só acontecerão se houver sensibilidade das autoridades e da própria sociedade como um todo é fator primordial para os avanços necessários.

\section{CONSIDERAÇÕES}

A temática educação por si só já é de bastante relevância no contexto dos avanços necessários de uma sociedade e se tratando da Educação Inclusiva potencializa-se ainda mais, afinal é através de perspectivas onde todos possam ter suas oportunidades garantidas para o ingresso e permanência na escola, tendo no ambiente escolar as necessárias condições para plena aprendizagem. É através dos estudos e pesquisas que uma nação tem as reais possibilidades de avanços 
constantes em todos as áreas de conhecimento. O tema abordado neste trabalho de pesquisa assim como outros pertinentes a educação são fundamentais para compreendermos o real valor da escola e suas contribuições no processo de consolidação dos saberes do educando para a construção do seu caráter cidadão.

Sempre que nos deparamos com o contexto da educação é natural que existam desafios e na Educação Inclusiva é que isso fica bastante evidente e muitas vezes até mesmo as dificuldades comuns diante dessa realidade principalmente na rede pública de ensino. O trabalho de pesquisa revelou que apesar dos grandes desafios da Educação Inclusiva mesmo que lentamente avanços aconteceram, mas é preciso percorrer ainda um caminho longo para que possamos nos aproximar do ideal.

A pesquisa realizada neste trabalho teve como proposta constatar através da fala dos autores pesquisados o fundamental papel da escola no desenvolvimento do individuo e a sua função integradora para que a Educação Inclusiva aconteça de fato. Os desafios e dificuldades enfrentados são inúmeros e principalmente na rede pública, remuneração abaixo do ideal, recursos materiais muitas vezes insuficientes ou até mesmo inexistentes, instalações em condições precárias nas instituições, esses são alguns dos motivos que desestimulam os educandos, famílias e professores.

A pesquisa mostrou que mesmo com muitas dificuldades é possível fazer a Educação Inclusiva acontecer, sem dúvidas que os recursos humanos e materiais fazem toda diferença, mas o educando deve ser prioridade. Para isso é preciso criatividade e inovação que são pilares no processo educativo, principalmente quando os recursos necessários são escassos, aí é que o professor engajado poderá fazer toda diferença tornando a sua sala de aula um espaço rico para aprendizagem. No entanto é preciso ressaltar que os recursos necessários disponibilizados, infraestrutura das escolas e a criatividade do professor são elementos primordiais para que o processo de ensino e aprendizagem aconteça plenamente.

A finalidade da pesquisa além de apontar os grandes desafios e as diversas dificuldades é também reconhecer que com ações propositivas é possível tornar a Educação Inclusiva no Brasil uma realidade que poderá transformar a vida do educando. 


\section{REFERÊNCIAS:}

BRASIL. Constituição (1988). Constituição (da) República Federativa do Brasil. Brasília: Senado Federal, 1988

BRASIL. Lei de Diretrizes e Bases da Educação Nacional. Lei 9394/96 | Lei no 9.394, de 20 de dezembro de 1996.

BRASIL. Declaração de Salamanca e linha de ação sobre necessidades educativas especiais. 2. ed. Brasília: CORDE,1997.

BRASIL. Diretrizes Nacionais para a Educação Especial na Educação Básica. Ministério da Educação. Secretaria de Educação Especial. Brasília:MEC/SEESP, 2001.

BRASIL. Ministério da Educação. O Desafio das Diferenças nas Escolas. Boletim 21. MEC, 2006.

SILVA, B.M.D.C; PEDRO, V.D.C; JESUS, E.M. Educação Inclusiva. Revista Científica Semana Acadêmica.Fortaleza. 2017

CARVALHO, R. E. Removendo Barreiras para a Aprendizagem. Educação Inclusiva. 8.ed, São Paulo: Saraiva, 2009.

MANTOAN, M.T. E. Inclusão escolar: o que é? Por que? como fazer? São Paulo: Moderna, 2003

PANAROTTO , J; SILVA, J. P.A Inclusão No Contexto Atual, São Paulo, 2014.

VYGOTSKY, L.S. A formação social da mente. São Paulo: Martins Fontes 1998. 